\title{
A Framework for Integrated Sustainability Assessment of Water Cycle Services
}

\author{
By H. Helness ${ }^{1}$, S. Damman ${ }^{2}$, W.P. de Clercq ${ }^{3}$, N.M. Elema ${ }^{3}$
}

\begin{abstract}
A methodology and a framework for integrated sustainability assessment of water cycle services to be used for analysis of strategic options in integrated water management has been developed. The hypothesis was that a holistic assessment framework based on local data would enable decisionmaking and sustainable development on a local scale in integrated water management. The SUWAM assessment framework was developed using the water cycle services of a small town in Western Cape, South Africa, as case. The point of departure was the municipality's plan for sustainable development. The suitability of the SUWAM Framework was assessed by comparison with two other frameworks: TRUST, from the EU-project TRUST, and City Blueprint, developed in an EIPwater action group. The comparison demonstrated that a sustainability assessment framework must: (i) be tailored to the local conditions, and (ii) that the perspective of the user, often a decision maker, must be taken into account in the interpretation of results. The methodology used in the development of the SUWAM Framework fulfilled these two criteria and produced results that were recognised as relevant for the studied case by local stakeholders. The methodology is suited for comparison and further analysis of different mitigation and adaptation measures.
\end{abstract}

Keywords: Integrated Water Management, Sustainability Assessment, Water Cycle Services

\section{Introduction}

Although climate change is expected to affect many sectors, water is considered the most critical factor associated with climate change impacts (CCI) and adaptability in South Africa (Kiker, 2000). The quantity and quality of water resources and their related ecosystem services (ESS) are of profound importance for sustainable development (SD). Utilisation of water is typically through man-made water cycle services (WCS) that can have many forms and purposes, e.g. irrigation systems, water supply and wastewater management infrastructure/-systems. The function and service levels of WCS are vulnerable to CCI, and WCS may have an impact on the water resources and related ESS through e.g. discharges and their efficiency in water use. There is, therefore, interdependency between water resources, water related ESS and WCS, and the impacts on society from climate change.

In a world with increasing water stress where CCI are expected to worsen the situation, increased resilience through sustainable water management is needed. To achieve this, one needs to analyse the current status and projected CCI on water resources and water related ESS with a focus on their impacts on society, and the sustainability of the WCS. The sustainability assessment should address technical, environmental and financial aspects of WCS, as well as socio-political dimensions such as equity, participation and poverty-reduction. 
Carden and Armitage, (2013) used a systems approach to measure sustainability in a South African urban water context, and what was required to meet the challenges of population growth, climate change and decreasing water quality. The resulting composite index, the 'Sustainability Index for Integrated Urban Water Management' (SIUWM) was developed with to link existing performance measurement processes in the South African water sector such as the Blue Drop and Green Drop benchmarking systems for water supply and sewerage, respectively, with a broader sustainability assessment process. The SIUWM index was applied to a number of case study cities in South Africa and highlighted some of the crisis areas in urban water management. The aim was to aid local authorities in establishing goals and inform strategic processes to leverage support for improved water services.

Sustainability assessment of WCS has also been studied in the European context e.g. in the EU-FP7 project TRUST where a framework for assessment of urban WCS (UWCS) was developed (Allegre et al., 2012). In TRUST, the assessment had the perspective of the service provider and his or her need to develop the services in a more sustainable manner. The UWCS sustainability was measured along the three classic dimensions of sustainability: environmental, financial and social, and in addition to these assets and governance (Allegre et al., 2012). The TRUST sustainability assessment framework (SAF) has been further developed in an European innovation partnership on water (EIP water) action group to assess the sustainability of water management in cities by a City Blueprint to be used as a baseline assessment and point of departure for strategic planning of improved UWCS (Van Leeuwen 2013). The original City Blueprint used 24 indicators, which were scored on a scale from zero to 10, and covered eight broad categories: water security, water quality, drinking water, sanitation, infrastructure, climate robustness, biodiversity and attractiveness, and governance. Recently the City Blueprint has been extended with two additional frameworks: The Trends and Pressures Framework (TPF), which assesses the main challenges, and the Governance Capacity Framework (GCF), which addresses improvement in governance, (Koop \& Leeuwen, 2016). The performance of the UWCS is assessed by the improved Blue City Framework (BCF*). The results from the TRUST and City Blueprint frameworks can be presented to show the scores of individual indicators e.g. in the form of a spider diagram, which also gives a comparison of the different dimensions. The City Blueprint Framework calculates the Blue City Index where the indicators have been aggregated in a median value.

In many cases, there is the need for a broader perspective on the sustainability of the WCS than the perspective held by the urban service provider or what can be measured by use of an index value focused on the urban water cycle. Sustainable urban water management is in many cases interlinked with sustainable management of water in the peri-urban environment. Also, the mentioned interdependency between water resources, water related ESS and WCS, and the impacts on society from climate change, necessitates that local societal development goals are integrated with national and general goals for sustainability in an integrated sustainability assessment.

This paper describes the development of a framework for such an Integrated Sustainability Assessment, referred to as the SUWAM Framework, based on a local municipality's Integrated Development Plan (IDP). In the South African Local 
Government context, the IDP is regarded as the "blue-print" framework for strategic planning of the local municipality, and is developed and implemented by the municipality as required by the Local Government Municipal Systems Act (Act 32/2000). The IDP is developed in conjunction with stakeholders who include the municipality, councillors, communities and other stakeholders and National and provincial governments departments. The IDP further has a five-year life span, after which it is reviewed and updated.

The chosen case for the study was Riversdale in Hessequa Municipality, in the Western Cape, South Africa, and the surrounding area using the Korente-Vette Government Water Scheme (KVGWS) as water source.

\section{Methods}

The starting point for development of the SAF was the municipality's IDP (HM, 2014) with the locally defined key performance areas (KPAs):

i. Effective communication and participation

ii. To limit the impact of our presence in the natural environment and re-establish a heritage of preservation

iii. Maintenance and development of all infrastructure and services

iv. Development of safe and integrated human settlements

v. Human development initiatives to enhance the social well-being of all our residents

vi. To stimulate economic growth for the benefit of all communities

vii. An accountable local authority with a fit for purpose workforce and transparent financial practices In development of the SUWAM framework, the following steps were performed:

1. The KPA of the local IDP were classified according to the five sustainability dimensions as used in the TRUST Framework, and water related objectives were formulated for each KPA.

2. To measure progress towards fulfilling the objectives, fulfilment criteria were formulated for each objective, and metrics for the measurement of progress were proposed.

3. The objectives, criteria and metrics were discussed with representatives from the local WCS provider and other local stakeholders to secure relevance in determining detailed indicators and data sources, in order to enable the quantification of indicator values.

4. The indicator values were quantified using local data from e.g. the municipal water services development plan (WSDP). Where no local data could be found, use of alternative indicators or national statistics was assessed and the most appropriate data chosen.

The sustainability of the WCS according to the TRUST Framework, was assessed using the on-line TRUST - self-assessment tool (TRUST, 2014). The City Blueprint was assessed according to the procedure given by (European Commission, 2015)). The results from the three different frameworks were compared at dimension level to discuss strengths and weaknesses of the different frameworks and the need for local adaptation. 


\section{Results and Discussion}

The seven KPAs or focus areas of the IDP defined by the Hessequa municipal council are operationalised in the municipal planning process by means of predetermined objectives. They are the municipality's objectives for development of the society in general terms. To apply them in water management a link must be made to the water cycle services in the area. The WCS in the area supplied by the Korente-Vette Government Water Scheme (KVGWS) are illustrated in Figure 1, and include both water supply services related to the town of Riversdale and the farmers' irrigation channel. The owner of the KVGWS is the Department of Water and Sanitation (DWS), who sets the operating rules for the Korentepoort dam and allocates water between the town and irrigation channel, while the practical management of this allocation of water for the town and irrigation to the different farmers is the task of the local irrigation board.

From the municipality's perspective, it is the maintenance and development of the water infrastructure downstream of the reservoirs and the service level within the municipality's area of responsibility that is in focus. This focus is in alignment with the KPA Maintenance and development of all infrastructure and services, and was formulated at objective level in the SAF as: Maintain adequate infrastructure for water supply and sanitation, with optimal impact on other infrastructure and services, and further detailed at criteria level with six criteria to enable measurement of progress towards fulfilling this objective:

A11 Hydraulic reliability for Riversdale, i.e. the ratio between demand and supply

A12 Coverage of water supply

A13 Coverage of sanitation

A14 Total operating costs cost per $\mathrm{m}^{3}$ of water and sewage

A15 Percent water loss

A16 Reduced potential for flooding

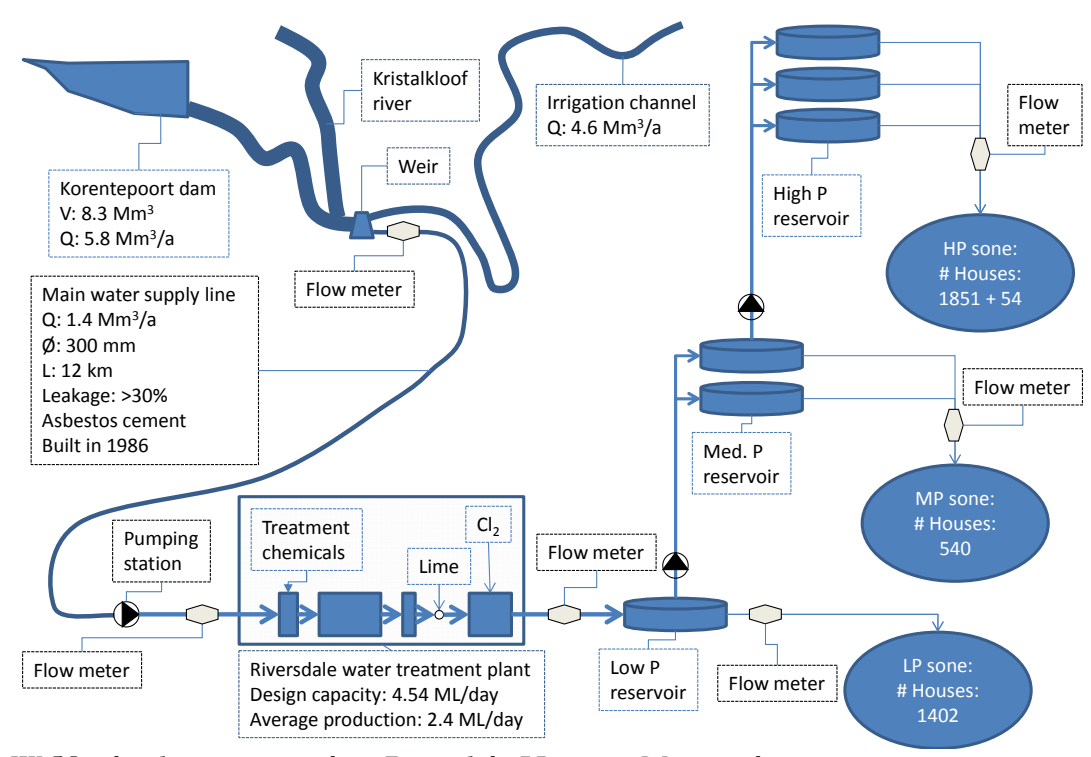

Figure 1. WCS related to water supply in Riversdale, Hessequa Municipality 
The same process of formulating a water specific objective in alignment with the KPA, followed by a development of criteria to measure progress towards fulfilling the objective, was also used for the other KPAs. Development of the criteria and indicators and selection of data sources was based on using local data before regional, national or literature data from other regions. The rationale was that although data may be limited and inaccurate, these local data sources are what the local stakeholders and decision makers use in forming their opinions on water management options. Local data was therefore considered most relevant, and use of them would also serve to highlight shortcomings and where measures to improve data were needed. The developed SAF is given in Table 1. A total of 29 criteria were developed to cover the different sustainability dimensions. Of these, only 5 made use of non-local data sources to quantify the current situation. These were related to communicative events on water management, where use of national statistics was chosen, energy consumption per household, $\mathrm{CO}_{2}$ footprint for potable water use and costs of water supply and sanitation for a household, where an on-line calculator developed by a Norwegian industry cluster (Smart Water Cluster, 2014) was used, and potential increase of employment in agriculture where data from DWA was chosen since they were responsible for the water allocation in the KVGWS. Of the local data sources the municipality's WSDP was most used, and supplemented with information given directly from personnel from the technical services department, environmental services department and community services department.

The results for the different criteria presented here are for the current situation. However, the framework was developed with an eye to the possibility of assessing future options in water management. This is reflected in some of the criteria, e.g. Share of increased water availability that benefits the community (municipality) and Acceptability of the strategic alternative, which implicitly refer to a future scenario and therefore have no value or zero value in the current situation. Assessment of future scenarios with regards to CCI on water availability and ESS, and the strategic options in water management the municipality may use for adaptation and mitigation, is beyond the scope of this paper. However, such options were already to some extent indicated in the municipality's planning, and were further developed during the work with the SAF. The point to be made in this context is that besides the use of local data, an assessment framework will need criteria that are relevant to the known future options and can therefore not be developed independently of these. The objectives and criteria will be discussed further together with the indicator values presented below. 
Table 1. SAF for WCS in Riversdale

\begin{tabular}{|c|c|c|c|c|c|c|}
\hline Dimention & KPA\# & $\begin{array}{l}\text { Alignment with Hessequa } \\
\text { Municipality's focus areas }\end{array}$ & ID & Objectives & ID & $\begin{array}{l}\text { Criteria for sustainability assessment of options in } \\
\qquad \text { IWM }\end{array}$ \\
\hline \multirow{8}{*}{ Social (S) } & \multirow{2}{*}{1} & \multirow{2}{*}{$\begin{array}{c}\text { EFFECTIVE } \\
\text { COMMUNICATION AND } \\
\text { PARTICIPATION. }\end{array}$} & \multirow{2}{*}{ S1 } & \multirow{2}{*}{$\begin{array}{l}\text { Increased participation in water } \\
\text { management }\end{array}$} & s11 & Actors involved in water resource management \\
\hline & & & & & S12 & Communicative events on water amangement \\
\hline & \multirow{3}{*}{4} & \multirow{3}{*}{$\begin{array}{l}\text { DEVELOPMENT OF SAFE AND } \\
\text { INTEGRATED HUMAN } \\
\text { SETTLEMENTS. }\end{array}$} & \multirow{3}{*}{ S2 } & \multirow{3}{*}{$\begin{array}{l}\text { Equitable access to reliable water } \\
\text { supply and acceptable sanitation }\end{array}$} & $\$ 21$ & Level of service for water supply. \\
\hline & & & & & S22 & Level of service for sanitation. \\
\hline & & & & & $\$ 23$ & $\begin{array}{l}\text { Share of increased water availability that benefits the } \\
\text { community (municipality) }\end{array}$ \\
\hline & \multirow{3}{*}{5} & \multirow{3}{*}{$\begin{array}{l}\text { HUMAN DEVELOPMENT } \\
\text { INITIATIVES TO ENHANCE } \\
\text { THE SOCIAL WELL-BEING OF } \\
\text { ALL OUR RESIDENTS. }\end{array}$} & \multirow{3}{*}{ s3 } & \multirow{3}{*}{$\begin{array}{l}\text { Water management solutions that } \\
\text { enhance good health, knowledge- } \\
\text { building and social integration }\end{array}$} & s31 & Compliance with quality standards \\
\hline & & & & & $\$ 32$ & Acceptability of the strategic alternative \\
\hline & & & & & 533 & Awareness of climate change \\
\hline \multirow{7}{*}{ Environment (En) } & \multirow{7}{*}{2} & \multirow{7}{*}{$\begin{array}{l}\text { TO LIMIT THE IMPACT OF } \\
\text { OUR PRESENCE IN THE } \\
\text { NATURAL ENVIRONMENT } \\
\text { AND REESTABLISH A } \\
\text { HERITAGE OF } \\
\text { PRESERVATION. }\end{array}$} & \multirow{4}{*}{ En1 } & \multirow{4}{*}{$\begin{array}{l}\text { Preserve water resources and water } \\
\text { related ecosystem services }\end{array}$} & En11 & Overall hydraulic reliability \\
\hline & & & & & En12 & Biodiversity \\
\hline & & & & & En13 & $\begin{array}{l}\text { Water resources provisioning of plants and animal } \\
\text { foodstuffs }\end{array}$ \\
\hline & & & & & En14 & Non renewable resource use of WCS \\
\hline & & & \multirow{3}{*}{ En2 } & \multirow{3}{*}{$\begin{array}{l}\text { Minimisation of other environmental } \\
\text { impacts }\end{array}$} & En21 & Energy consumption per household \\
\hline & & & & & En22 & CO2 footprint for potable water use \\
\hline & & & & & En23 & Flow downstream Riversdale for different needs \\
\hline \multirow{5}{*}{ Economic (Ec) } & \multirow{5}{*}{6} & \multirow{5}{*}{$\begin{array}{l}\text { TO STIMULATE ECONOMIC } \\
\text { GROWTH FOR THE BENEFIT } \\
\text { OF ALL COMMUNITIES. }\end{array}$} & \multirow{5}{*}{ Ec1 } & \multirow{5}{*}{$\begin{array}{l}\text { Stimulate economic growth and } \\
\text { entrepreneurship through better access } \\
\text { to water resources and improved water } \\
\text { cycle services }\end{array}$} & Ec11 & Hydraulic reliability for irrigation channel \\
\hline & & & & & Ec12 & $\begin{array}{l}\text { Total cost for water supply and sanitation for a } \\
\text { houshold }\end{array}$ \\
\hline & & & & & Ec13 & Potential increase of employment in agriculture \\
\hline & & & & & Ec14 & $\begin{array}{l}\text { Extent of land and/or number of farms that can be } \\
\text { irrigated }\end{array}$ \\
\hline & & & & & Ec15 & Water beyond basic needs \\
\hline \multirow{3}{*}{ Governance (G) } & \multirow{3}{*}{7} & \multirow{3}{*}{$\begin{array}{l}\text { AN ACCOUNTABLE LOCAL } \\
\text { AUTHORITY WITH A FIT FOR } \\
\text { PURPOSE WORKFORCE AND } \\
\text { TRANSPARENT FINANCIAL } \\
\text { PRACTICES. }\end{array}$} & \multirow{3}{*}{ G1 } & \multirow{3}{*}{$\begin{array}{l}\text { Deliver services in alignment with } \\
\text { prevailing standards for good } \\
\text { governance in water management }\end{array}$} & G11 & Compliance with Blue drop; Green drop; No drop \\
\hline & & & & & G12 & Fraction of billed water tarifs recieved as income. \\
\hline & & & & & G13 & $\begin{array}{l}\text { Impact in terms of roles and networks, distribution of } \\
\text { resources in the implicated institutions, transparancy }\end{array}$ \\
\hline \multirow{6}{*}{ Assets (A) } & & & & & A11 & Hydraulic reliability for Riversdale water supply \\
\hline & & & & & A12 & Infrastructure for water supply and sanitation \\
\hline & 3 & $\begin{array}{l}\text { MAINTENANCE AND } \\
\text { DEVELOPMENT OF ALL }\end{array}$ & 11 & $\begin{array}{l}\text { Maintain adequate infrastructure for } \\
\text { water supply and sanitation, with }\end{array}$ & A13 & $\begin{array}{l}\text { Operation and maintenance of water supply and } \\
\text { sanitation infrastructure }\end{array}$ \\
\hline & & SERVICES & & $\begin{array}{l}\text { optimal impact on other infrastructure } \\
\text { and services }\end{array}$ & A14 & Total operating costs cost per $\mathrm{m} 3$ of water and sewage \\
\hline & & & & & A15 & Water loss \\
\hline & & & & & A16 & Reduced potential for flooding \\
\hline
\end{tabular}




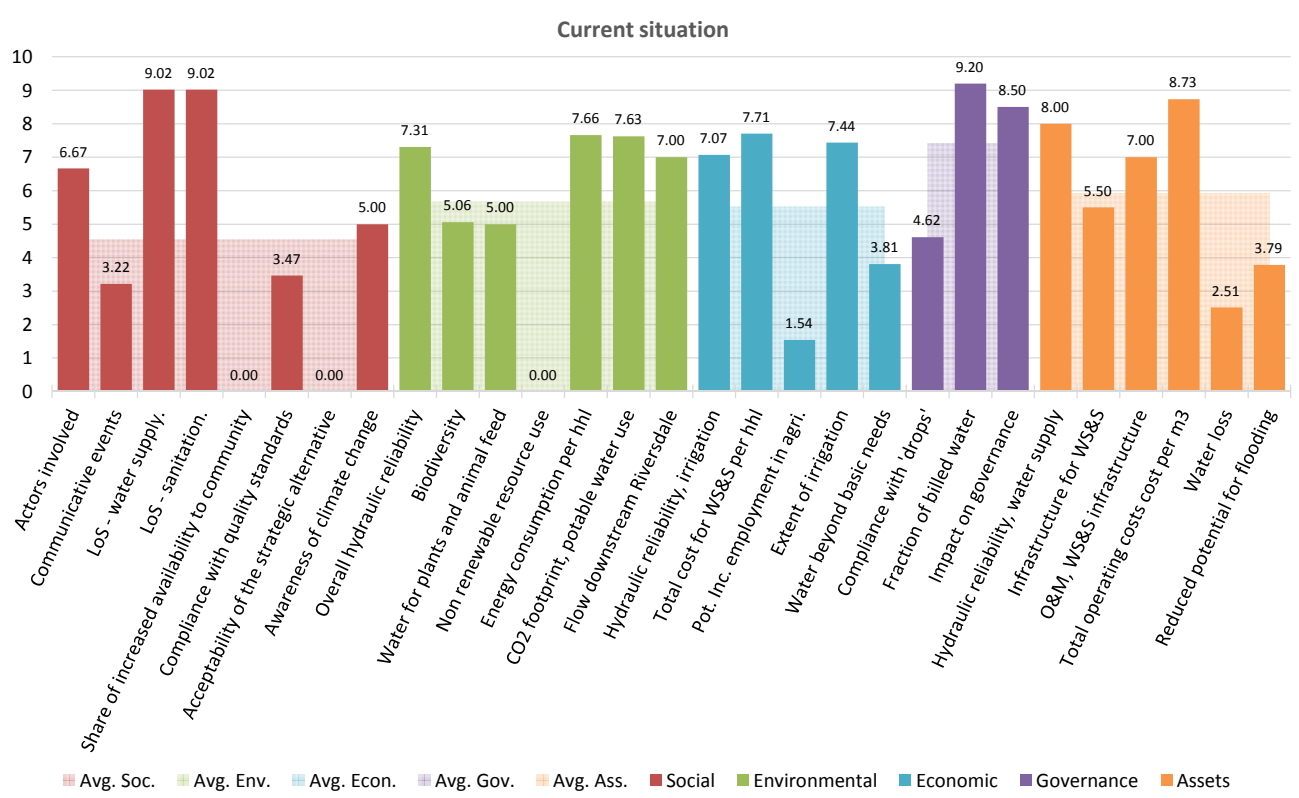

Figure 2 Results from Riverdale in the SUW AM Framework.

The results for Riverdale in the SUWAM Framework, with values for the current situation, are shown in Figure 2. The scores presented are normalised to a scale of 0 to 10 where 0 indicates very poor conditions and 10 is a perfect score. The range used for the normalisation was in most cases given by the logical scale, e.g. 0 to $100 \%$. However, expert opinion was used in some cases, e.g. Water loss was normalised using $50 \%$ loss as a maximum value since this was considered to represent a very poor but realistic maximum for this criterion.

When considering the mean values for all the scores in the different dimensions, the results with the SUWAM Framework indicated that the sustainability of the WCS in Riversdale and the surrounding area supplied by the KVGWS have an average score for the social, environmental, economic and assets dimensions, and a higher than average score for governance. Lower than average scores for the individual social criteria, were found related to Communicative events and Compliance with quality standards. The highest scores in the social dimension were found for the criteria Level of service for water supply and Level of service for sanitation, which were both high.

For the environmental dimension, the assessments of Overall bydraulic reliability, Nonrenewable resource use of WCS, Biodiversity and Water resources provisioning of plants and animal foodstuffs, points to limited water availability, lack of water reuse and criteria related to biodiversity, as areas of concern. The criteria related to energy use and required ecological flow downstream, however, show above average scores.

In the economic dimension, limitation with respect to available water resources resulted in lower than average scores for the criteria related economic growth, i.e. the Potential for increased employment in agriculture, and Water availability beyond basic needs, which may potentially be used for economic gain. The criteria related to costs and water allocation 
for irrigation today, achieved higher than average scores.

The scores for governance criteria were higher than average except for Compliance with the blue drop and green drop evaluation schemes. The blue and green 'drops' cover both quality, monitoring and management, and address water supply and sanitation, respectively. In this case, the low scores relate to non-compliance with respect to monitoring frequency and management system issues, while water quality per se, was within the required standards.

In the assets dimension, the scores for Water loss, Reduced potential for flooding and Infrastructure for water supply and sanitation were lower than average, and pointed to leakages and issues related to infrastructure as areas of concern. The scores for operating costs, and the criterion related to operation and maintenance achieved higher than average scores. The criterion for water availability, Hydraulic reliability for water supply, also had a higher than average score for the current situation. However, water availability was considered to be an issue of concern for the future.

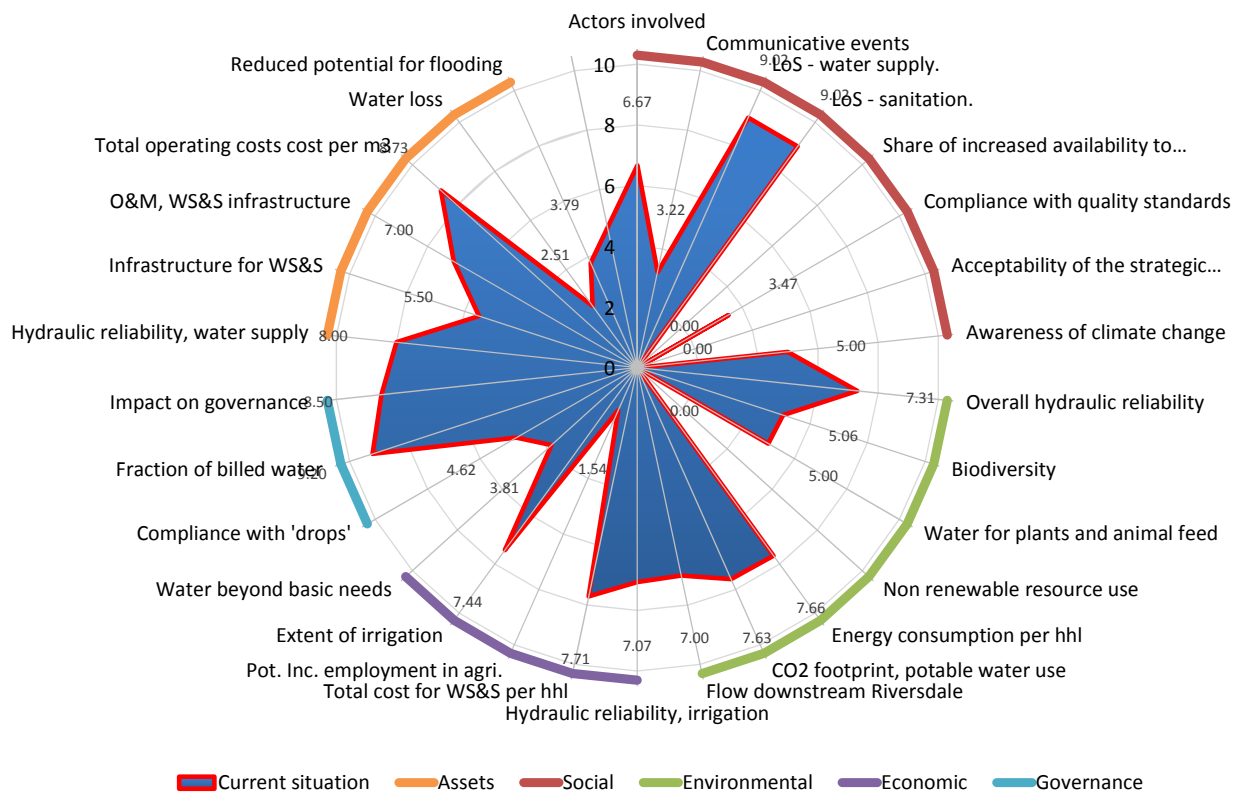

Figure 5 Spider diagram of the results for Riversdale with the SUWAM

\section{Evaluation and comparison with other frameworks}

In a sustainability assessment, one should use a holistic approach and consider total sustainability, given the weighting of criteria and dimensions provided by the stakeholders. Presenting the results in a spider diagram as shown in Figure 5, may provide a better visual impression of sustainability than bar charts, and can account for the difference perceived between criteria and dimensions, as opposed to a single total average or median value presented to represent a sustainability index. It is also useful in further analysis to assess the effects of weighting and comparison of different mitigation 
or adaptation measures and strategies.

To provide an absolute score with respect to sustainability of the WCS is in most cases not possible or required. It is, however, crucial that the assessment is deemed relevant by the local stakeholders, and that the level of detail is sufficient for the level of assessment whether it be strategic, tactical or operational (Stuart and Scott, 1995). In this study, a mid-term evaluation was performed using the Payback-Eco method (Elema et al., 2015). A selected group of local stakeholders were consulted through a standard questionnaire, amongst other asking if the research performed had or was expected to have impacts on knowledge production, policy, societal conditions or ecological conditions. An overall positive response with respect to expected future impacts indicated relevance and supported the approach.

The results according to the SUWAM SAF can be compared to the results found when using the TRUST Framework and the City Blueprint Framework in Figure 3 and Figure 4 , respectively.

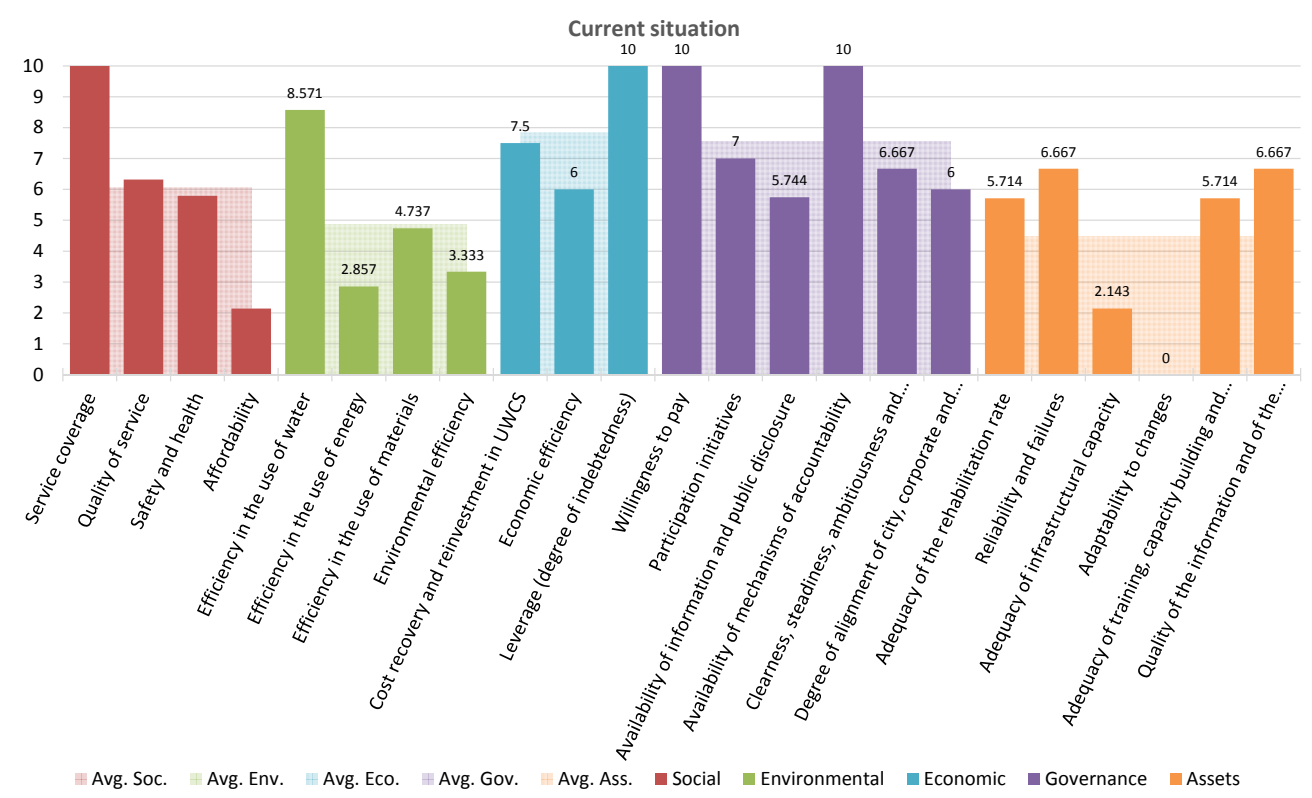

Figure 3 Results from Riverdale in the TRUST Framework 


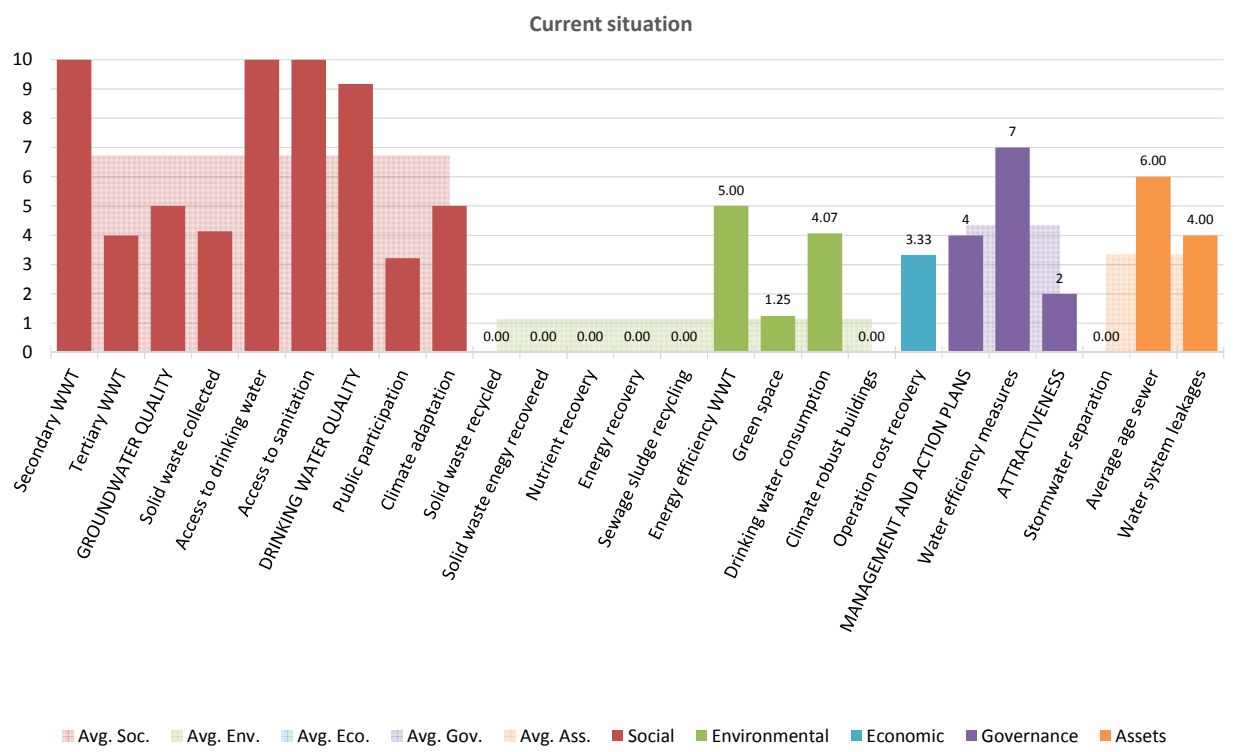

Figure 4 Results from Riverdale in the City Blueprint Framework (CBF)

Compared to the TRUST Framework (Figure 3), the SUWAM Framework has comparable average scores for the social, environmental and governance dimensions. The assets dimension has a lower score in the TRUST Framework, due to the criterion on Adaptability to changes. In the economic dimension, however, the average score is higher than for the SUWAM Framework. This is because the criteria in TRUST focus on issues related to the service delivery and not economic development of the society in general, and shows the effect using a framework that was developed from the service provider's perspective.

The City Blueprint approach is a comprehensive assessment tool for assessment of the water cycle management in large cities. In Figure 4, the BCF results for Riversdale are presented. Compared to the SUWAM and TRUST frameworks, a clear difference can be seen in the number of criteria in each sustainability dimension. In the CBF, there is an emphasis on the IWRM performance of a city and the two largest groups of indicators address the social and environmental dimensions. Two other complementary frameworks in the City Blueprint Approach address trends and pressures, and governance capacity. Also noteworthy is that while the average score in the social dimension is comparable to the scores found in the SUWAM and TRUST frameworks, the average score for the environmental dimension is overall low. The reason for this is the zero score for Riverdale on all of the criteria related to recycling of resources and the low score for Green space. Recycling normally requires a certain scale to be cost effective and green space is a criterion most relevant for large cities. The seemingly underperformance of Riversdale in the environmental dimension according to the CBF, can therefore be ascribed to the difference in scale between the small town of Riversdale and large cities for which the CBF was intended.

The comparison of the results from the different frameworks demonstrate that a 
sustainability assessment framework must be tailored to the local conditions of the case assessed, and that the perspective of the user, often a decision maker, must accompany the interpretation of the results. The methodology used in the development of the SUWAM Framework, where the point of departure was the local plan for sustainable development, fulfilled these two criteria and therefore produced a sustainability assessment of the WCS, with results that were relevant for the studied case and recognised as such by local stakeholders.

\section{Conclusions}

The comparison of the results from the different frameworks demonstrated that a sustainability assessment framework must be tailored to the local conditions in the case that is assessed, and that the perspective of the user, often a decision maker must be taken into account in the interpretation of the results. The methodology used in the development of the SUWAM Framework, where the point of departure was a local plan for sustainable development, fulfilled these two criteria and therefore produced a sustainability assessment of the WCS with results that were relevant for the studied case and recognised as such by local stakeholders.

The methodology is suited for comparison and further analysis of different mitigation and adaptation measures.

\section{Acknowledgements}

We would like to express our sincere thanks to the staff and management of Hessequa Municipality and the other stakeholders who contributed to the study. We would also like to thank the Research Council of Norway and the National Research Foundation of South Africa for funding this research.

\section{References}

Alegre, H., Brattebø, H., Cabrera Jr, E. and Hein, A. (2012). Framework for Sustainability Assessment of UWCS and development of a self-assessment tool D 31.1, www.trust-i.net - info@trust-i.net.

Carden, K., \& Armitage, N. P. (2013). Assessing urban water sustainability in South Africa-not just performance measurement. Water $S A, 39(3), 345-350$.

Elema, N. M., Mouton, J. M., \& Cloete, T. E. (2015). 'The Payback-Eco Framework: Measuring the Impact of Scientific Research in the Water Sector and experiences from the WARFSA Funded Research (1999-2014)'. Conference Special session: Waternet/W ARFS A/GWP-SA Symposium. Mauritius.

European Commission. (2015). European Innovation Partnership on Water. Brussels, Belgium. http://www.eip-water.eu/City_Blueprints, accessed November 2015.

HM (2014). Hessequa $3^{\text {rd }}$ generation Integrated Development Plan, 2012-2017. Draft, $2^{\text {nd }}$ review. Hessequa Municipality. $\quad$ https://www.westerncape.gov.za/text/2014/April/hessequa-draft-idp-20122017.pdf, accessed May 2014.

Kiker, G.A. (2000). South African Coutrny Study on Climate Change: Synthesis report for the vulnerability and adaptation section, University of Kwazulu Natal.

Koop, S. H. A., \& Leeuwen, C. J. (2016). The challenges of water, waste and climate change in cities. Environment, Development and Sustainability, 1-34.

Republic of South Africa (2000). Local Government: Municipal Systems Act. Act 32/2000. Pretoria, South Africa. 
Smart Water Cluster (2014). http://smartwatercluster.no/wp-content/uploads/2014/05 /EndeligSmartWaterModellenedCH3.swf, accessed November 2015.

Stewart, T. J., \& Scott, L. (1995). A Scenario-Based Framework for Multicriteria Decision Analysis in Water Resources Planning. Water Resources Research, 31(11), 2835-2843.

TRUST (2014). http://www.trust-i.net/tools/index.php?iddesc=107, accessed November 2015.

Van Leeuwen, C. J. (2013). City Blueprints: Baseline assessment of sustainable water management in 11 cities of the future. Water Resources Management, 27, 5191-5206. 